\title{
Premature Failure on Low-Grade R.C. Beams Reinforced with Bonded Steel Plate
}

\author{
Wensheng $\mathrm{Li}^{*}$ and Zhili Qian \\ Department of Civil Engineering, School of Urban Construction, Yangtze University, Jingzhou Hubei, China \\ ${ }^{*}$ Corresponding author
}

\begin{abstract}
Based on the experimental results and theoretical analysis, the study of the classification and mechanism of the premature failure for low-grade R.C. beams reinforced with bonded steel plate is placed on, finally, reasonable measure to overcome the premature failure is introduced..
\end{abstract}

Keywords- low-grade R.C. beams; reinforced with bonded steel plate; premature failure; the interaction coefficient

\section{INTRODUCTION}

After the implementation of reinforcing with bonded steel plate of low-grade R.C. beams, we ensure the improving of the bending performance, also hope to realize the ductile failure of component at the same time. In practice, however, it is found that it is prone to the phenomenon of debonding failure of the end or midspan of plate when they are at the lack of reliable anchorage between reinforcing steel and original beam. And the actual capability of bearing bending is much lower than the theoretical value of the normal bending failure (the steel and steel plate yield and have a certain extension of ductility, and the concrete is crushed when they are at failure) when the damage occurs. We call this phenomenon as premature failure on R.C. beams reinforced with bonded steel plate.

\section{TEST SECTION}

In the test of R.C. beams reinforced with bonded steel plate ${ }^{[1]}$,we poured a total of ten low-grade R.C. beams as A, B, C three groups, and they were tested the capability of bearing bending of two-point loading of three equal respectively (FIGURE I DIAGRAM FOR BEAMS). Among them, the four of group A, for the comparison, were directly loaded but not reinforced; the four of group B were R.C. beams reinforced with bonded steel plate of first loading of reinforcing before loading; the two of group $\mathrm{C}$ were R.C. beams reinforced with bonded steel plate of secondary loading of loading to cracked and reinforcing and continuing loading. Table 1 was the summary of undermined results for R.C. beams reinforced with bonded steel plate (groups B and C). We can see that it is a common phenomenon of the premature failure on low-grade R.C. beams reinforced with bonded steel plate.

TABLE I. LIST OF TEST FAILURE OF R.C. BEAMS REINFORCED WITH BONDED STEEL PLATE

\begin{tabular}{|c|c|c|c|c|c|c|c|c|}
\hline \multirow[b]{2}{*}{$\begin{array}{l}\text { Number of } \\
\text { Beams }\end{array}$} & \multirow[b]{2}{*}{$\begin{array}{l}\text { Strength of } \\
\text { Concrete }\end{array}$} & \multicolumn{2}{|c|}{$\begin{array}{l}\text { The measured strain } \\
(\times 10 \mathrm{E}-6)\end{array}$} & \multirow[b]{2}{*}{$\begin{array}{c}\text { Failure } \\
\text { modes }\end{array}$} & \multirow[b]{2}{*}{$\begin{array}{c}\text { Values of } \\
\text { theory } \mathbf{M}_{\mathrm{u}}{ }^{\mathrm{c}} \\
(\mathbf{k N} \cdot \mathbf{m})\end{array}$} & \multirow[b]{2}{*}{$\begin{array}{c}\text { Values of } \\
\text { test } \\
\mathbf{M}_{\mathbf{u}}{ }^{t} \\
(\mathbf{k N} \cdot \mathbf{m})\end{array}$} & \multirow[b]{2}{*}{$\mathbf{M}_{\mathbf{u}}^{\mathrm{t}} / \mathbf{M}_{\mathbf{u}}{ }^{\mathrm{c}}$} & \multirow[b]{2}{*}{ Notes } \\
\hline & & $\begin{array}{c}\text { The } \\
\text { original } \\
\text { beam } \\
\text { reinforceme } \\
n\end{array}$ & $\begin{array}{l}\text { Reinforcem } \\
\text { ent plate }\end{array}$ & & & & & \\
\hline LB1 & C7.5 & 417 & 457 & $\begin{array}{l}\text { Premature failure of } \\
\text { degumming of the } \\
\text { end }\end{array}$ & 34.2 & 20.1 & 0.59 & $\begin{array}{l}\text { Steels and plates } \\
\text { did not yield }\end{array}$ \\
\hline LB2 & C10 & 1017 & 1216 & $\begin{array}{l}\text { Premature failure of } \\
\text { degumming of the } \\
\text { end }\end{array}$ & 36.2 & 25.2 & 0.70 & $\begin{array}{l}\text { Steels and plates } \\
\text { did not yield }\end{array}$ \\
\hline LB3 & C15 & 1324 & 1564 & $\begin{array}{l}\text { Premature failure of } \\
\text { degumming of the } \\
\text { end }\end{array}$ & 38.3 & 35.1 & 0.92 & $\begin{array}{l}\text { Steels and plates } \\
\text { did not yield }\end{array}$ \\
\hline LB4 & $\mathrm{C} 20$ & 3570 & 4382 & Normal failure & 39.3 & 40.1 & 1.02 & $\begin{array}{c}\text { Steels and plates } \\
\text { yielded }\end{array}$ \\
\hline LC3 & C15 & 1893 & 1195 & $\begin{array}{c}\text { Premature failure of } \\
\text { degumming of the } \\
\text { midspan }\end{array}$ & 38.4 & 23.2 & 0.60 & $\begin{array}{l}\text { Plates did not } \\
\text { yield }\end{array}$ \\
\hline LC4 & C20 & 1588 & 1234 & $\begin{array}{l}\text { Premature failure of } \\
\text { degumming of the } \\
\text { midspan }\end{array}$ & 39.3 & 25.7 & 0.65 & $\begin{array}{l}\text { Plates did not } \\
\text { yield }\end{array}$ \\
\hline
\end{tabular}




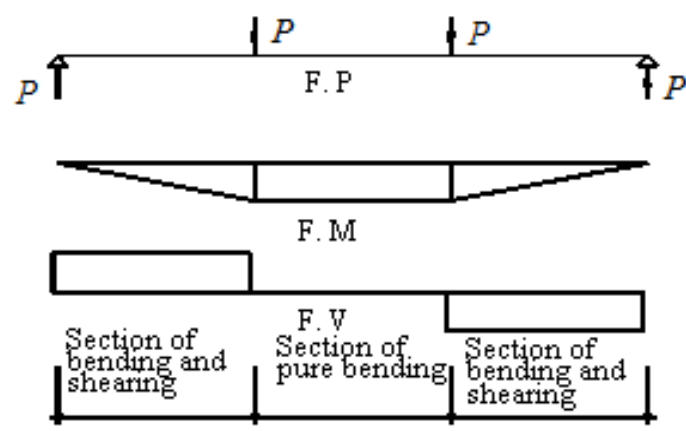

FIGURE I.

DIAGRAM FOR BEAMS

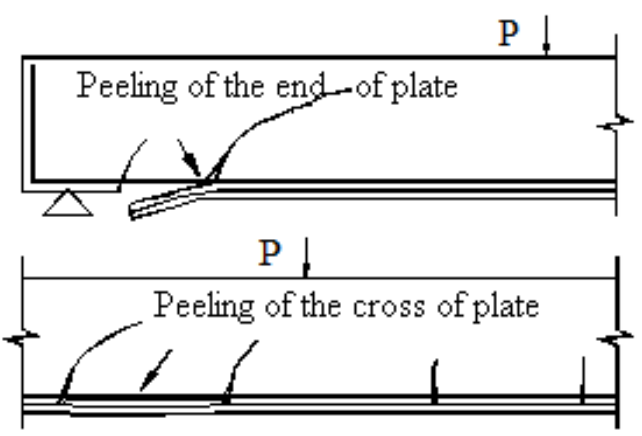

FIGURE II.

PREMATURE FAILURE OF PEELING OF THE END (MIDSPAN) OF PLATE

\section{A. Premature Failure of Peeling of the End of Plate}

As FIGURE II shown, reinforced beam LB1, 2 of first loading had the common characteristics of destruction: as the load increases, the concrete of the end of plate produced vertical micro-cracks firstly, then they became inclined cracks and stretches to the direction of concentrated force. As the load continued, concrete of the end of plate of incidental part was teared suddenly along the inner surface of concrete cover of the beam and extends along the direction of longitudinal steel extremely quickly. Beams declared failure as the brittle cracking of peeling. Steel and plate did not yield, and the failure occurred suddenly with a very poor ductility when it came.

\section{B. Premature Failure of Peeling of the Midspan of Plate}

As FIGURE II shown, reinforced beams LC3, 4 of secondary loading had the common characteristics of destruction: with the load increased, within two cracks having the shorter spacing of sections of bending and shearing between the bearing and the concentrated force, it suddenly appeared that the plate with concrete cover from the end of beam peels along the direction of longitudinal steel after reinforcing with steel plate; loaded again, peeling of the plate extended to two side quickly, and it appeared the peeling of the plate with big area. No load added up. Beams declared failure. Because they were components of secondary loading, the steel reached the yield strain for the leading of strain but the plate was far from the yield strain for the lagging of strain when the failure came, and it occurred suddenly with a very poor ductility.

\section{MECHANISM OF PREMATURE FAILURE ON R.C. BEAMS REINFORCED WITH BONDED STEEL PLATE}

\section{A. Bonding Shear Stress between the Plate and R.C. Beams}

Take micro-element $d x$ of section of shearing span of reinforced beam for objects (as FIGURE III shown) to study the bonding shear stress between the plate and R.C. beams. Because beams are in elastic phase in the premature failure. Strain of normal section should meet the plane-section assumption.

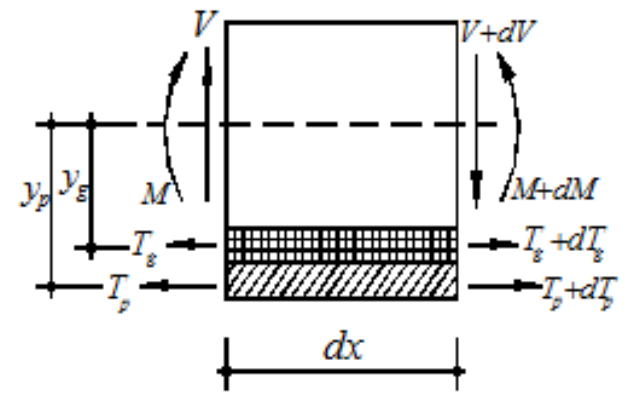

FIGURE III. DIAGRAM OF MICRO-ELEMENT OF REINFORCED BEAM

1) Bonding shear stress between the plate and bonding adhesive layer: The force balance equation

$$
T_{p}+d T_{p}-T_{p}=\tau_{p g} b_{p} d x
$$

By bending theory

$$
\frac{d T_{p}}{A_{p} E_{p}}=\frac{d M \cdot y_{p}}{I_{T} E_{c}}=\frac{V \cdot d x \cdot y_{p}}{I_{T} E_{c}}
$$

To sum up

$$
\tau_{p g}=\frac{1}{b_{p}} \frac{d T_{p}}{d x}=\frac{V \cdot A_{p} \cdot y_{p} \cdot \alpha_{p c}}{I_{T} b_{p}}
$$

Among them, the $\tau_{p g}$ is the bonding stress between the adhesive layer and plate bonding interface; $b_{p}$ is width of the steel plate section; $A_{p}$ is the area of the steel plate section; $y_{p}$ is the distance from neutral axis to the midline of steel plate section; $\alpha_{p c}$ is the elastic modulus ratio of steel plate and concrete $\left(\alpha_{p c}=\frac{E_{p}}{E_{c}} \approx 8.0\right) ; I_{T}$ is the moment of inertia of the concrete section converted by entire section.

2) Bonding shear stress between the adhesive layer and the concrete bonding interface: The force balance equation

$$
\tau_{g c}=\frac{d T_{p}+d T_{g}}{b_{g} \cdot d x}
$$

By bending theory

$$
\frac{d T_{g}}{A_{g} E_{g}}=\frac{d M \cdot y_{g}}{I_{T} E_{c}}=\frac{V \cdot d x \cdot y_{g}}{I_{T} E_{c}}
$$




$$
d T_{g}=\frac{V \cdot d x \cdot y_{g} \cdot \alpha_{g c} \cdot A_{g}}{I_{T}}
$$

Among them, the $\tau_{g c}$ is the bonding shear stress between the adhesive layer and the concrete bonding interface; $b_{g}$ is the width of plastic section; $A_{g}$ is the area of the plastic section; $y_{g}$ is the distance from neutral axis to the midline of plastic section; $\alpha_{g c}$ is the elastic modulus ratio of adhesive layer and the concrete ( $\alpha_{g c}=\frac{E_{g}}{E_{c}}=0.03 \sim 0.3$ ).

Because of $b_{g}=b_{p}, A_{g} \approx A_{p}, \alpha_{p c} / \alpha_{g c}=27 \sim 270$, so for the $d T_{p}, d T_{g}$ can be negligible, and it is obtained:

$$
\tau_{g c}=\tau_{p g}=\frac{V \cdot A_{p} \cdot y_{p} \cdot \alpha_{p c}}{I_{T} b_{p}}=\frac{V \cdot y_{p} \cdot \alpha_{p c} \cdot t_{p}}{I_{T}}
$$

Combining the experimental results and the theoretical analysis above, it is known that premature failure of low-grade R.C. beams reinforced with bonded steel plate generally occurs in the section of bending and shearing of beams generally. This is because the bonding shear stress between the steel plate and concrete is caused by the rate of bending moment of beam which is the shearing force of beam section, and it increases with the increasing of shearing force.

\section{B. Mechanism of Peeling Failure of the Midspan of Steel Plate}

As FIGURE IV shown, within the section of bending and shearing, the concrete cover between two adjacent cracks taken as the studying object, bonding shear stress $\tau_{g c}$ acted on its joint surface of steel plate and the end of R.C. beams, ignoring the interaction of adjacent concrete and assuming the bonding shear stress $\tau_{g c}$ to be distributed evenly. The work status of concrete cover within cracks was as a cantilever beam. To explore the stress status of point $A$ :

To balance the bonding shear stress $\tau_{g c}$, there must be inverse shear stress in the bonding interface $A B$ of the steel and concrete. Shear stress of point $A$ is $\tau_{A}=\tau_{g c} \frac{b_{g}}{b}$,

To balance the trend of torsion formed by bonding shear stress, there must be tension and compression stress in the bonding interface $A B$ of the steel and concrete. Normal stress of point A is $\sigma_{A}=\frac{M_{A} l_{c r}}{2 I_{A}}$, in which the $I_{A}$ is section moment of inertia of concrete bonding interface within cracks, $I_{A}=b l_{c r}^{3} / 12 ; M_{A}$ is the torsion caused by bonding shear stress, $M_{A}=\tau_{g c} \cdot l_{c r} b_{g} c ; l_{c r}$ is the crack spacing; $c$ is the thickness of concrete cover.

In all kinds of material strength of adhesive layer, shear and tensile strength of the concrete itself is poor. When the bonding shear stress $\tau_{A}$ that point $\mathrm{A}$ born met the shear strength of concrete $f_{c v}$, the section generated bonding shear failure; when the peeling tensile stress $\sigma_{A}$ that point A born met the tensile strength of concrete $f_{t}$, the section generated stripping failure of the steel plate, and they formed peeling failure of steel plate together. There are peeling failure equation: $\tau_{A} \leq f_{c v}$ and $\sigma_{A} \leq f_{t}$.

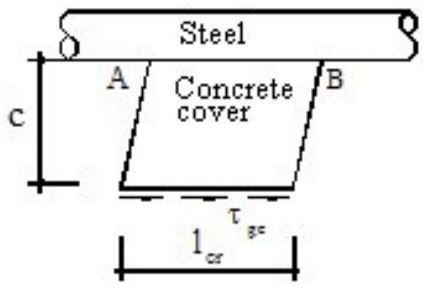

FIGURE IV. THE STRESS OF CONCRETE COVER BETWEEN ADJACENT CRACKS

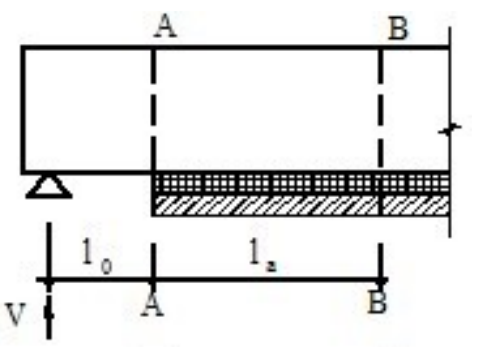

FIGURE V. ANCHORAGE ZONE OF PLATE

In fact, bonding shear stress is not evenly distributed, bonding shear failure often occurs in the peak of shear stress, however, peeling tensile stress is effected by crack spacing $l_{c r}$ in a large extent. The shorter the crack spacing is, the bigger the peeling tensile stress is. For beam reinforced with bonded steel plate of secondary loading, it has been loaded before sticking steel, so the concrete of the end of beam can be pulled cracking easily; after sticking steel, due to the section of bending and shearing being near concentrated force, moment and shear force of section are larger. Within two cracks having the shorter spacing of sections of bending and shearing in the midspan of reinforcement beam, it occurs firstly and easily of the phenomenon of peeling failure of the midspan of steel plate.

\section{Mechanism of Peeling Failure of the End of Steel Plate}

1) The bonding shear stress of the end of plate: As FIGURE V shown, within anchorage area of the bearing and the end of plate, reinforced steel plate begins from A-A section, and the distance from bearing is $l_{0}$; B-B section is the place of fully functioning of steel plate. $l_{a}$ is the length of anchoring section. Tensile stress $\sigma_{p}$ of reinforcing steel plate is equal to 
0 in A-A section, in the B-B section:

$$
\sigma_{p}=\frac{M_{B} \cdot y_{p} \cdot \alpha_{p c}}{I_{T}}=\frac{V\left(l_{0}+l_{a}\right) \cdot y_{p} \cdot \alpha_{p c}}{I_{T}} .
$$

Then the average bonding shear stress $\frac{\bar{\tau}}{\tau}$ between the steel plate of the $\mathrm{x}$ and concrete is:

$$
\bar{\tau}=\frac{\sigma_{p} A_{p}}{l_{a}}=\left(1+\frac{l_{0}}{l_{a}}\right) \frac{V \cdot y_{p} \cdot \alpha_{p c} \cdot t_{p}}{I_{T}},
$$

which shows that when the anchorage length $l_{a}$ is insufficient, it will lead to the increase of the average bonding shear stress.

2) Peeling stress of the end of plate: Referring to FIGURE IV and the formula

$$
\sigma_{A}=\frac{M_{A} l_{c r}}{2 I_{A}}
$$

changing $l_{c r}$ to $l_{a}$, it is also known that, to balance the torsion formed by the bonding shear stress, when there is tensile stress at the end of reinforced steel plate (called the peeling tensile stress) and the anchorage length is insufficient, peeling tensile stress will increase. It is the stress concentration (shear and tensile stress) generated at the end of reinforced steel plate that causes the bonding failure of the end of steel plate or the peeling failure of the concrete cover.

\section{SimplifiEd CALCULATION AND ANCHORING}

\section{A. Simplified Calculation of the Anchoring Length}

It is given of simplified calculation formula of anchorage length of bonded steel plate in Code for the Strengthening [2] But it does not take the peeling tensile stress of the end of steel plate into account, and this is its shortcoming.

\section{B. The Calculation of Bearing Capability Considering the Interaction Coefficient}

In order to ensure the reliability of the strengthened components, in the calculation of bearing capability, it is proposed to introduce the interaction coefficient $\beta$ to take factors of premature failure into account. Combined with the calculation formula of bearing capability of normal bending failure of R.C. beams reinforced with bonded steel plate, the following formulas are given:

$$
\begin{gathered}
f_{c} b x+f_{y}^{\prime} A_{s}^{\prime}=f_{y} A_{s}+\beta \cdot f_{p} A_{p} \\
M_{u}=f_{c} b x\left(h_{0}-x / 2\right)+f_{y}^{\prime} A_{s}^{\prime}\left(h_{0}-a_{s}^{\prime}\right)+\beta \cdot f_{p} A_{p}\left(a_{s}+t_{p} / 2\right)
\end{gathered}
$$

For R.C. beams reinforced with bonded steel plate of excellent adhesion or anchoring measures, it is proposed that $\beta=0.8 \sim 0.9$; for general R.C. beams reinforced with bonded steel plate, it depends on the effect of reinforcement.

\section{Anchoring of Reinforcing Steel}

For R.C. beams reinforced with bonded steel plate born of first loading, even the anchorage length of steel plate calculated according to the formula of Code for the Strengthening ${ }^{[2]}$ meets requirements, it should also be considered adding the U-shaped hoop plate or bolt anchorage ${ }^{[3]}$ on the end of plate in the structure to eliminate the effect of stress concentration and to prevent the premature peeling failure on the end. Considering the end of frame beam usually being dense area of hoop reinforcement, it is difficult to anchor the end of plate with bolt, but $\mathrm{U}$-shaped hoop plate is appropriate.

For R.C. beams reinforced with bonded steel plate of secondary loading, at the time of bonding steel plate, the bending cracks often have been generated in the section of bending and shearing of reinforced beam. There also are bonding shear stress and peeling tensile stress between the steel plate and concrete, and it will make the steel plates of the section of bending and shearing fall off from the concrete. Therefore, additional anchorage measure must be taken. For example a number of U-shaped hoop plate or bolt anchorage ${ }^{[3]}$ should be set evenly along the reinforced plate.

\section{CONCLUSION}

Due to the existence of bonding shear stress and peeling tensile stress on the bonding interface of steel plate and concrete, it makes the phenomena of premature peeling failure of R.C. beams reinforced with bonded steel plate within the section of bending and shearing of the end of plate and the midspan of beam easily. Premature failure occurs suddenly, and the tensile strength of the steel plate is not being fully utilized, and it is a brittle failure. The interaction coefficients need to be taken to reflect the impact of premature failure in the calculation of bearing capability of R.C. beams reinforced with bonded steel plate. Meanwhile, the anchorage measure should be taken to the reinforced plate.

\section{REFERENCES}

[1] Li Wensheng, Experimental study and theoretical analysis on reinforced concrete beams strengthened by bonded steel plates [D]. Wuhan: Master's thesis of Wuhan University of Technology. 2002.

[2] 2013 GB.Code for design of strengthening concrete structure[S][D]. Beijing: China Architecture \& Building Press,2013.

[3] Cao Shuangyin and Sun Yongxin, Experimental study of the performances of bonding and anchoring on beams reinforced with steel plate and suggestions, 2nd ed., vol.30. Industrial Construction, 2000, pp.6-7 